\title{
Mini Review: Oxazolidinone and Other Sialic Acid C5 Modifications over the Past Decade
}

\author{
Regina Salmasan* \\ Department of Chemistry, De La Salle University, Manila
}

\begin{abstract}
The potential of sialic acids as therapeutic agents has gradually been recognized due to its importance in the proper functioning of living systems, and likewise the virulence of several pathogens. However, synthesis of these compounds often result in poor yields and selectivities because of inherent characteristics associated with their structures. Use of various promoters, solvent systems and introduction of auxiliaries has since improved the outlook of chemical sialylation. Of these, attachment of various groups on C5 has notably resulted in improved $\alpha$-selectivity. This mini review focuses on C5 structural modification of sialic acids over the past decade, most notably the oxazolidinone group protection.
\end{abstract}

Keywords: sialic acid; C5 modification; oxazolidinone; a-sialylation

\section{PHYSIOLOGICAL SIGNIFICANCE OF SIALIC ACIDS}

Sialic acids are cyclic nine-carbon monosaccharides discovered in the 1930s by Gunnar Blix as a product of the mild acid hydrolysis of salivary mucins but not introduced to the scientific community until 1952 (Varki and Schauer, 2009; Lundblad, 2015). These are also present in other body fluids such as serum, urine and human milk, with the highest concentration found in colostrum and decreasing as lactation progresses (Wang and Brand-Miller, 2003). Commonly found in the non-reducing, terminal positions of glycans and glycoconjugates, sialic acids have significant roles in cell interactions and the development of vertebrates (Varki, 1993; Schauer, 2000).
In humans, sialic acid in the form of 5-N-acetyl neuraminic acid (Neu5Ac) is found in high concentration in the brain gangliosides (Wang and Brand-Miller, 2003) with no significant differences between sexes. However, concentration variations observed in the left and right lobes of human and chimpanzee brains suggest its significance in the development of various neurological functions (Suzuki, Pattern, 1965; Wang et al., Sialic, 1998). Although there are conflicting reports on whether the increase or decrease of sialic acid concentration in the brain leads to psychiatric and neurodegenerative disorders, in general, alterations in the level of brain sialic acid have been linked to conditions such as schizophrenia (Sirota et al., 1988; Sato and Kitajima, 2013; Schnaar et al., 2014; Piras et al., 2015), phenylketonuria (Loo et al., 1985) and Alzheimer's disease (Schedin-Weiss et al., 2014).

\footnotetext{
*Author to whom correspondence should be addressed; email: regina.salmasan@dlsu.edu.ph
} 
Gangliosides in the nervous system may also serve as markers of other medical conditions. In diabetic rat liver, increased expression of monosialogangliosides GM1 and GM3, disialoganglioside GD1b and trisialoganglioside GT1b, with a marked absence of GM2 were found (Sanchez et al., 2000; Abregu et al., 2002). Rats subjected under a high fructose and glucose diet showed elevated sialic acid synthesis in the liver and kidney with concomitant loss of sialic acids in the pancreas (Ibrahim et al., 2016).

Cancerous tissues also express increased levels of bound sialic acid (Ingraham and Alhadeff, 1978). Elevated concentrations were seen in the brain, liver, testes and kidney of Dalton's lymphoma-bearing mice (Nicol and Prasad, 2002). While in human melanomas, the disialogangliosides GD2 and GD3 are reported to be largely expressed (Hussain et al., 2011).

In addition, sialic acids were found to be important receptors in the entry of viruses, such as influenza, into humans and other hosts. Influenza A and B, of avian origin, both have hemagglutinin and neuraminidase which interact with Neu5Ac, while influenza C contains hemagglutinin-esterase-fusion (HEF) protein and interacts primarily with $\mathrm{Neu} 5,9 \mathrm{Ac}_{2}$. Sialic acid linkages to galactose (Gal), N-acetylgalactosamine (GalNAc) or Nacetylglucosamine (GlcNAc) also affect the binding of influenza viruses. Avian influenza viruses primarily bind to Neu5Ac in $\alpha 2-3$ linkage with $G$ al while human influenza viruses bind to Neu5Ac in $\alpha 2-6$ Gal linkage (Matrosovich et al., 2015; Stencel-Baerenwald et al., 2014; Sauer et al., 2014; Mandal et al., 2015; Varki and Gagneux, 2012). Studies utilizing other animal models such as mice (Pekosz et al., 2009) and horses (Suzuki et al., Sialic, 2000) have shown that receptor specificity is important in the replication of the virus. The extracellular matrix glycoprotein called fibronectin was reportedly essential in the entry of viruses with $\alpha 2-6$ linkage preference (Leung et al., 2012).

Due to the importance of sialic acids in physiology and pathogenesis, researches are now targeting the potential of these compounds in the production of pharmaceuticals (Liao et al., 2015; Spence et al., 2015; Zhang et al., 2014; Byrne et al., 2007; Kiefel and von Itzstein, 2002). Unfortunately, extraction of sialic acids and its derivatives in adequate amounts from natural sources is very challenging. Synthetic strategies have also been limited by the inherent characteristics of sialic acid which include the destabilization of the oxocarbenium ion due to the presence of carboxylic acid and the absence of a directing group near the anomeric position. Thus, synthetic chemists have continuously sought for ways to improve chemical sialylation. These include investigations on various promoter systems (Salmasan et al., 2014; Crich and Li, 2006; Ress and Linhardt, 2004) and structural variations via attachment of auxiliaries (in $\mathrm{C} 1$, C3, C5) or modification of the hydroxyl groups (at C4, C7, C8, C9) (Ress and Linhardt, 2004; Boons and Demchenko, 2000). Among these modifications, the attachment of various electron-withdrawing groups on C5 have brought significant improvements in yield and $\alpha$-selectivity (Hanashima, 2011; Crich, 2011; Hemeon and Bennet, 2007; Halcomb and Chappell, 2002; Boons and Demchenko, 2000). Much of the current researches are still exploring this potential in the hopes of achieving a more efficient sialylation, sometimes even without the assistance of nitrile solvents. Acetonitrile or propionitrile have been commonly employed as solvents in $\alpha$-sialylation as these interact with the $\beta$-face of the oxocarbenium ion thereby improving $\alpha$ selectivity (Hasegawa et al., 1991). This mini review focuses on $\mathrm{C} 5$ sialic acid modifications over the past decade, most notably the effect of oxazolidinone-protection on $\mathrm{C} 4,5$ and its combination with other protecting groups aimed towards better yield and stereoselectivity.

\section{OXAZOLIDINONE PROTECTION}

The 5-N,4-O-oxazolidinone protection of sialic acids is usually achieved by treatment of the free amine with $p$-nitro-phenyl chloroformate (NPCC), while deprotection is performed under basic conditions (Farris and De Meo, 2007; De Meo and Priyadarshani, 2008; Tanaka et al., Oligo, 2006). 

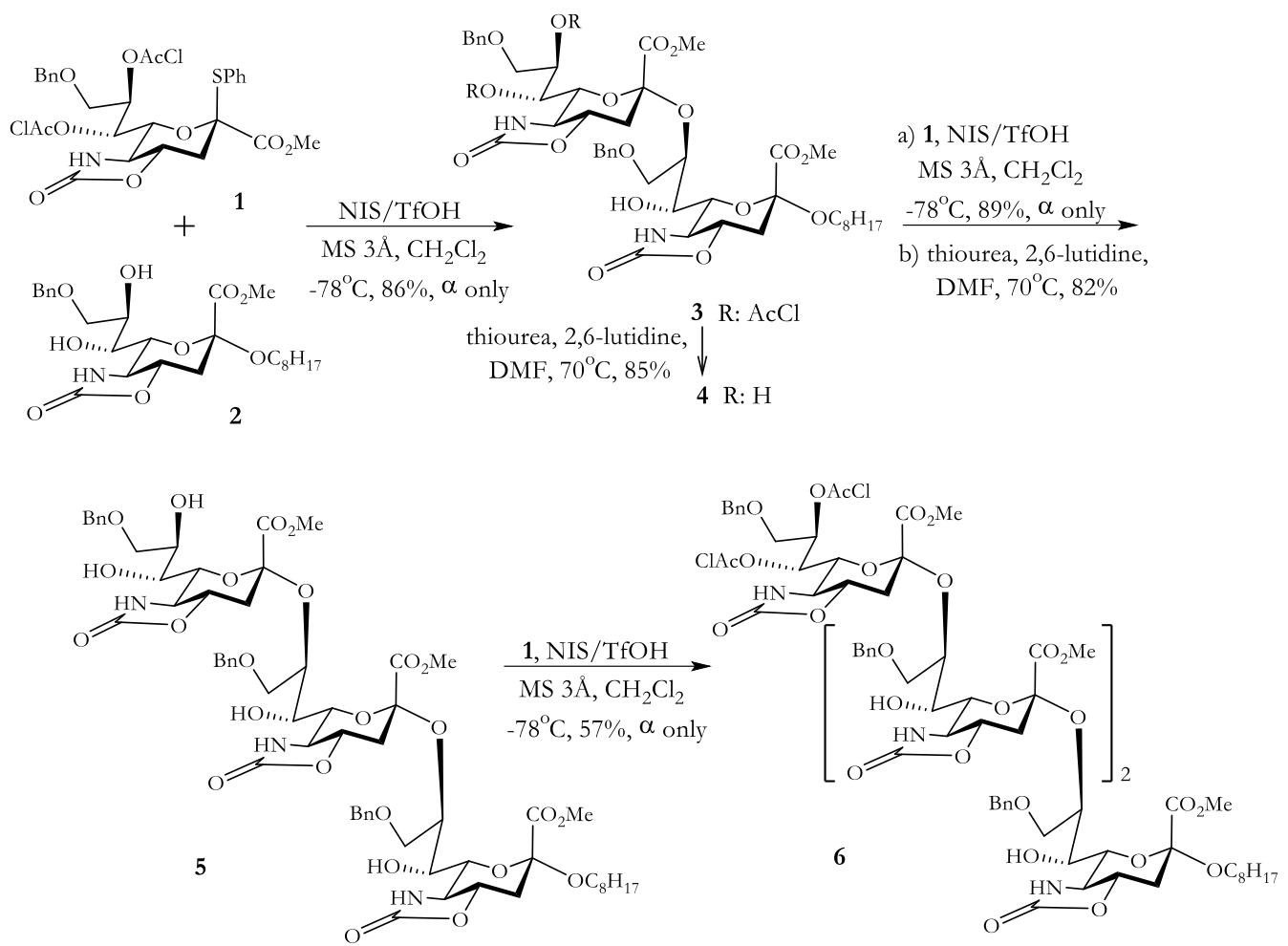

Figure 1. a(2,8)sialylation of oxazolidinone-protected donor and acceptor.

Protection of both donors and acceptors have facilitated the synthesis of $\alpha(2,8)$-tetrasialic acid even without the help of nitrile solvent effects. Coupling of $\mathbf{1}$ and $\mathbf{2}$ via $N$ iodosuccinimide/ trifluoromethanesulfonic acid (NIS/TfOH) activation (Figure 1) resulted in disialic acid $\mathbf{3}$ as the $\alpha$-anomer in $86 \%$ yield. Deprotection of the chloroacetyl groups afforded acceptor 4 . After subsequent iterative sialylation and deprotection, tetrasialic acid $\mathbf{6}$ was obtained in perfect stereoselectivity although in a lower yield of 57\% (Tanaka et al., Oligo, 2006).

The same method was also employed in the synthesis of $\alpha(2,9)$-di-, tri- and tetrasialic acids with excellent stereoselectivity $(\alpha: \beta=>95: 5)$ in overall yields of $87 \%, 89 \%$ and $69 \%$, respectively (Tanaka et al., Tetrasialic, 2009). These show that the oxazolidinone ring effectively enhances the reactivity of the hydroxyl group at C8 and that it provides an alternative in the sialylation of primary alcohols without the need for nitrile solvents. In both syntheses, removal of the oxazolidinone ring was done using lithium hydroxide (Tanaka et al., Oligo, 2006; Tanaka et al., Tetrasialic, 2009). In a similar set of reaction conditions but with the use of $\mathrm{CH}_{2} \mathrm{Cl}_{2} / \mathrm{CH}_{3} \mathrm{CN}$ as solvent, Lin and co-workers also reported the synthesis of $\alpha(2,9)$-tetrasialic acid by combining the effects of the oxazolidinone ring with tri-Ochloroacetyl protecting groups on C7, 8 and 9 of the thiosialoside donor. Utilizing acceptors with free hydroxyl groups on C7, 8 and 9, the fully deprotected $\alpha(2,9)$-tetrasialic acid was likewise obtained in perfect stereoselectivity although in lower overall yield (Lin et al., 2010). As evident in Tanaka and co-workers' results, the same trend of diminishing yield as the number of sialic acid residues on the chain increased was also observed. Ensuring the $\alpha$ selectivity of all linkages and prevention of random removal of the protecting groups are some of the factors that may hinder the elongation of the oligosialic acid chain. One way to overcome this is by using sialyl phosphate donors in a convergent block synthetic strategy. Coupling tetrasialic acid donor $\mathbf{7}$ and octasialoside acceptor $\mathbf{8}$ via trimethylsilyl trifluoromethanesulfonate (TMSOTf) activation (Figure 2), the $\alpha(2,9)$ dodecasialic acid 9 was obtained in 45\% yield (Chu et al., 2011). This is by far the longest oligosialic acid chain synthesized with an impressive yield. 


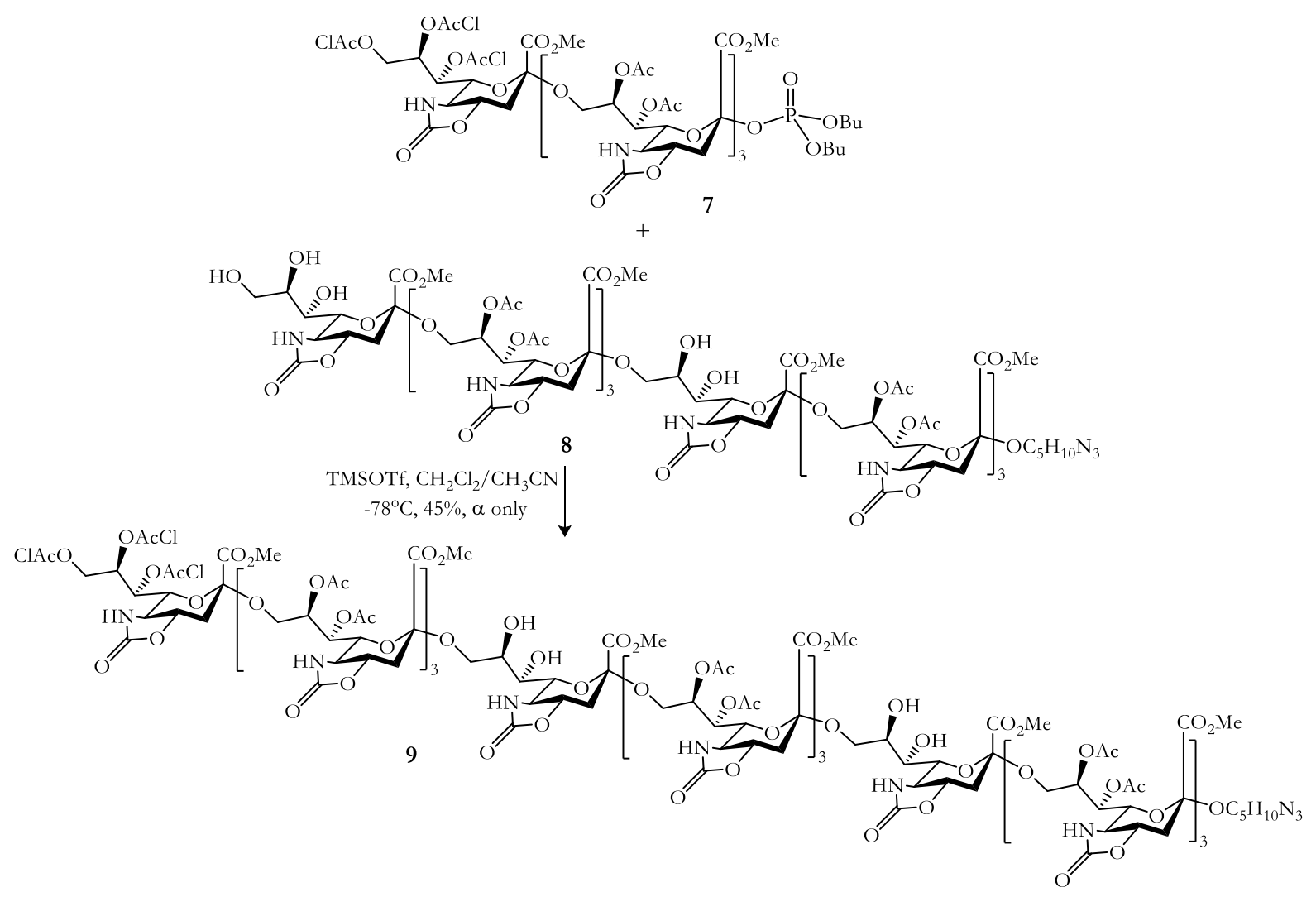

Figure 2. Synthesis of a $(2,9)$ dodecasialic acid.

Aside from $\alpha(2,8 / 9), \alpha(2,3 / 6)$ linkages are also common in glycoconjugates. While the latter can be synthesized in excellent yields, stereocontrol remains a challenge. Improvement in the stereoselectivity of $\alpha(2,6)$ sialylation was successful when the effects of oxazolidinone was combined with $S$ benzoxazolyl (SBox) at C2 in donor 10 (Figure 3). Selective activation of the sialyl thioimidate donor over the thioethyl galactoside acceptor 11 via bismuth (III) triflate activation in $\mathrm{CH}_{2} \mathrm{Cl}_{2}$ /THF afforded disaccharide 12 in $66 \%$ yield and 20:1 $\alpha / \beta$ ratio (Harris et al., 2011).

In the case of $\alpha(2,3)$ sialylations (Table 1$), p$ toluenethiosialoside 13 (Liang et al., 2009) with an acetyl group attached to the oxazolidinoneprotected nitrogen afforded comparable yields but markedly better selectivities than the previously reported phenylthiosialoside 14 (Crich and Li, O-Sialylation, 2007). Changing the activation method of $\mathbf{1 3}$ from NIS/TfOH to diphenylsulfoxide/ trifluoromethanesulfonic anhydride/2,4,6-tri-tert-butylpyridine $\left(\mathrm{Ph}_{2} \mathrm{SO} / \mathrm{Tf}_{2} \mathrm{O} / \mathrm{TTBPy}\right)$ afforded better selectivity $(\alpha / \beta$ ratio from $6.1: 1$ to $9.9: 1)$ in $\alpha(2,6)$ sialylation with a $6-\mathrm{OH}$ glucopyranoside acceptor (Wang et al., 2011).

Oxidation of the STol group in $\mathbf{1 3}$ using metachloroperoxybenzoic acid (m-CPBA) resulted in sialyl sulfoxide $\mathbf{1 5}$ (Figure 4). While sulfoxides have already been utilized in glycosylation, the potential of sialyl sulfoxides as donors have not been fully explored. Pioneering work by $\mathrm{Gu}$ and co-workers

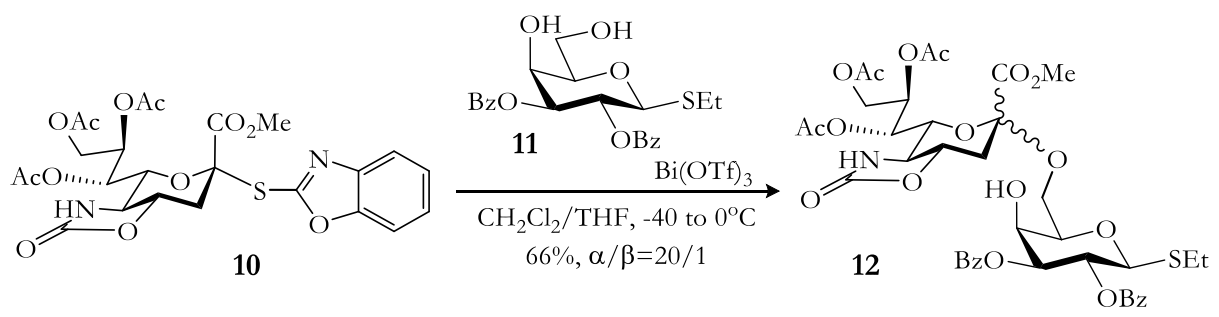

Figure 3. a(2,6) sialylation of oxazolidinone-protected S-benzoxazolyl sialyl donor. 
showed that activation of 15 using trifluoromethanesulfonic anhydride/ ditolyl sulfoxide $\left(\mathrm{Tf}_{2} \mathrm{O} /(\mathrm{Tol})_{2} \mathrm{SO}\right)$ facilitated the synthesis of $\alpha(2,3)$ - and $\alpha(2,4)$-sialosides (16$18)$ in good yields $(60-78 \%)$ and complete $\alpha$ selectivity ( $\mathrm{Gu}$ et al., 2012).

On the other hand, it was possible to synthesize non-natural GM4 derivatives via (2-2) and (2-4) sialylation using phenylthiosialoside 14 (Figure 5). Activation of 14 via $\mathrm{NIS} / \mathrm{TfOH}$ in $\mathrm{CH}_{3} \mathrm{CN} / \mathrm{CH}_{2} \mathrm{Cl}_{2}$ afforded the (2-2) linked GM4 derivative 19 in excellent yield with the predominance of the $\alpha$-anomer. This is in contrast to the result of the synthesis of (2-4) linked GM4 derivative $\mathbf{2 0}$ which only gave the $\beta$-anomer in $58 \%$ yield (Kurimoto et al., 2015).

The presence of $5 \mathrm{~N}$-tert-butoxycarbonyl (5-NBoc) group on the oxazolidinone ring 22 instead of acetyl has also been reported in the synthesis of a tetrasaccharide bearing a fucosyl linkage (Figure 6). While Boc and the fucosyl linkage are usually labile in acidic conditions, these were found to be stable under NIS/TMSOTf activation affording the tetrasaccharide 23 in $73 \%$ yield. The oxazolidinone group can also be selectively cleaved without affecting the Boc carbamate allowing further functionalization of the resulting amine (Boltje et al., 2013).

Further modification done by double-locking sialic acid 24 with oxazolidinone and siliconprotecting groups di-tert-butylsiloxanylidene (DTBS) on C5,7 and tetraisopropyldisiloxanylidene (TIPDS) on C8, 9 (Figure 7) gave trisaccharide $\mathbf{2 6}$ as the $\alpha$-anomer in $80 \%$ yield without the need for nitrile solvent. Using molecular modelling, the excellent $\alpha$ selectivity observed can be explained as a consequence of the clearly defined $\mathrm{R} e$ and $\mathrm{Si}$ faces of the oxonium ion due to the oxazolidinone and silylene groups. The latter blocking the $S i$ face thereby exposing the $\mathrm{R} e$ face to $\mathrm{TfOH}$ during activation. The $\mathrm{OH}$ group of the acceptor then approaches the $S i$ face which leads to the $\alpha$-anomer (Hanashima et al., 2009).

\section{OTHER MODIFICATIONS ON C5}

Significant improvements in sialylation observed when oxazolidinone is trans-fused to pyranose rings result from the strong influence of its dipole moment which creates an electron-withdrawing effect that causes the destabilization of the oxocarbenium ion. This destabilization then favors $\mathrm{S}_{\mathrm{N}} 2$-like mechanistic pathways (Kancharla et al., 2012). Capitalizing on this and the thiocarbonyl

Table 1. Comparison of $p$-Toluenethiosialoside 13 and Phenylthiosialoside $14 \alpha(2,3)$ Sialylations

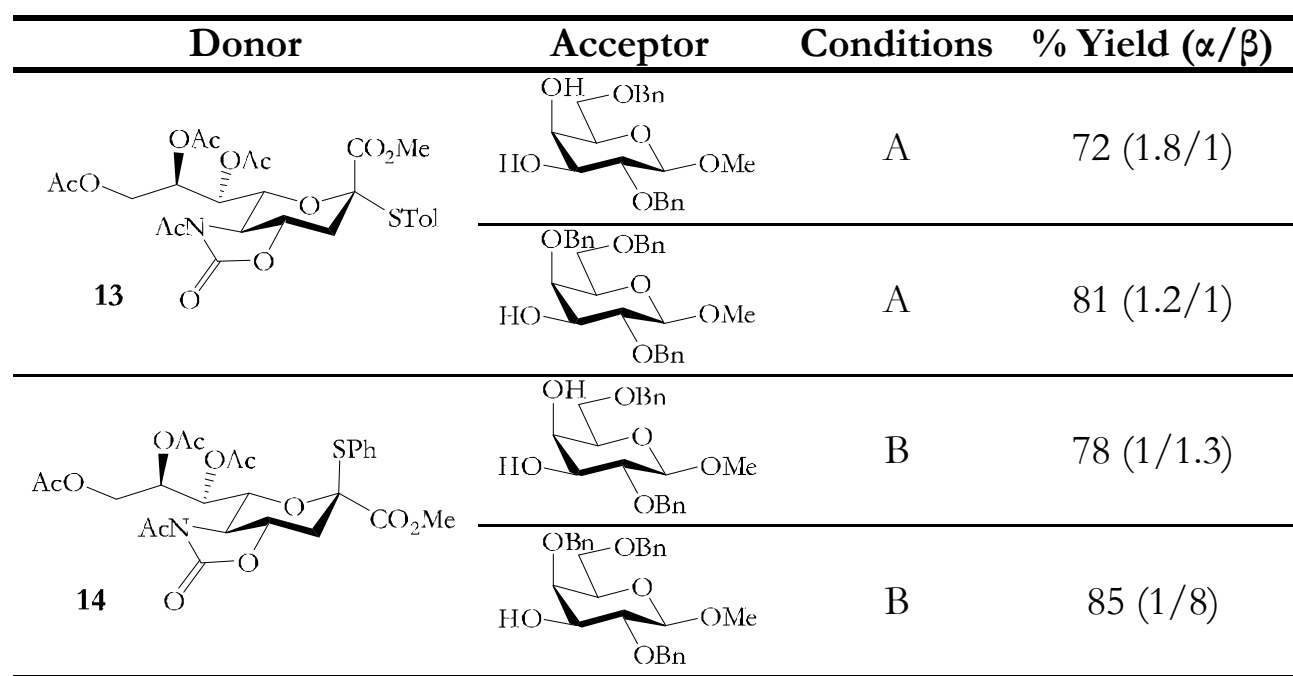

Conditions: A (Liang et al., 2009): NIS/TfOH. $\mathrm{CH}_{2} \mathrm{Cl}_{2} / \mathrm{CH}_{3} \mathrm{CN}, \mathrm{MS} 4 \AA,-40^{\circ} \mathrm{C}$; B (Crich and Li, O-Sialylation, 2007): NIS/TfOH, $\mathrm{CH}_{2} \mathrm{Cl}_{2}$, MS $5 \AA,-40^{\circ} \mathrm{C}$. 

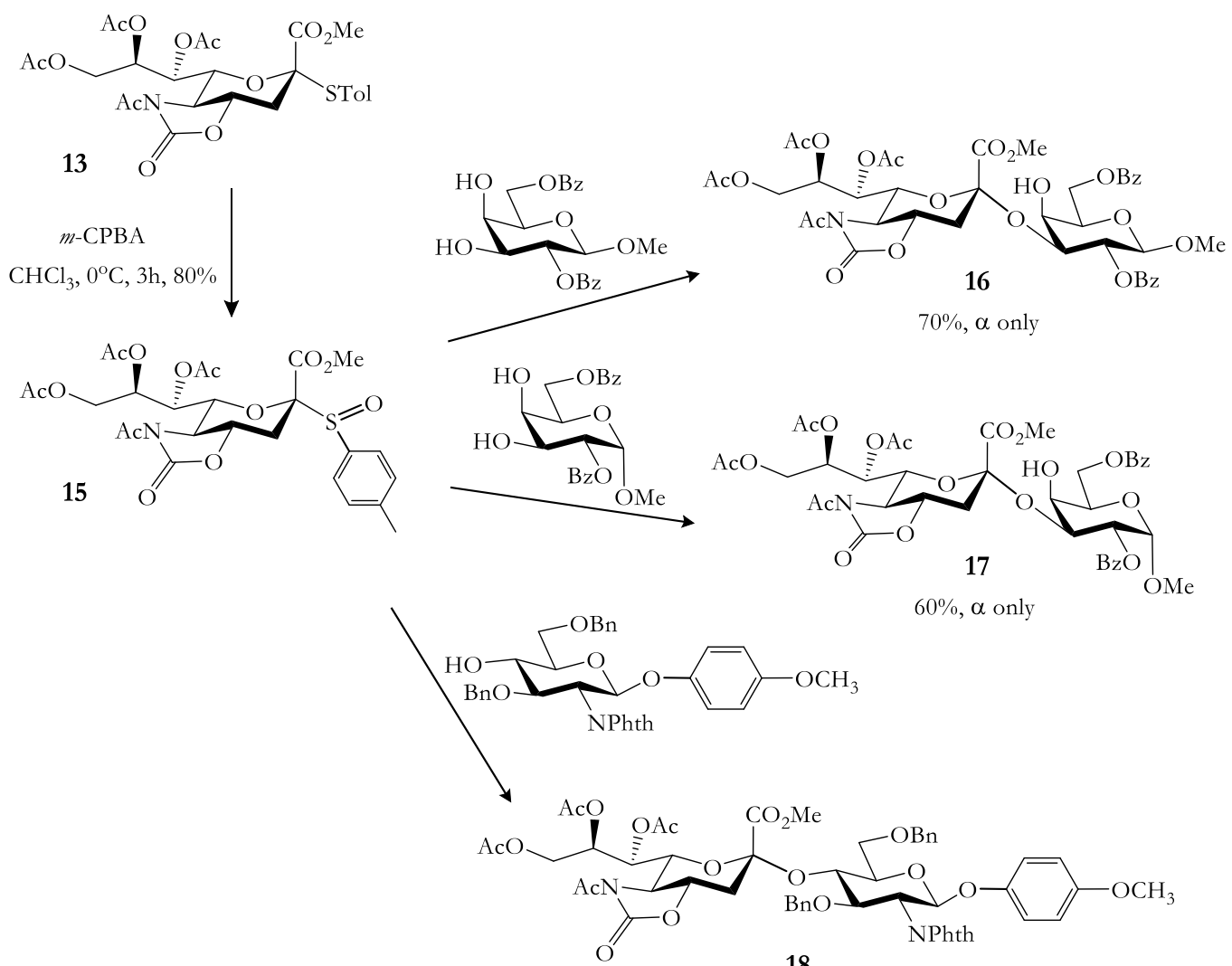

18

$78 \%, \alpha$ only

Figure 4. Synthesis of a(2,3)- and a(2,4)-sialosides using sialyl sulfoxide donor 15. Sialylation conditions: $\mathrm{Tf}_{2} \mathrm{O} /(\mathrm{Tol})_{2} \mathrm{SO}$ (2.0 equiv), $\mathrm{MS} 4 \AA, \mathrm{CH}_{2} \mathrm{Cl}_{2},-70$ to $-50^{\circ} \mathrm{C}$.

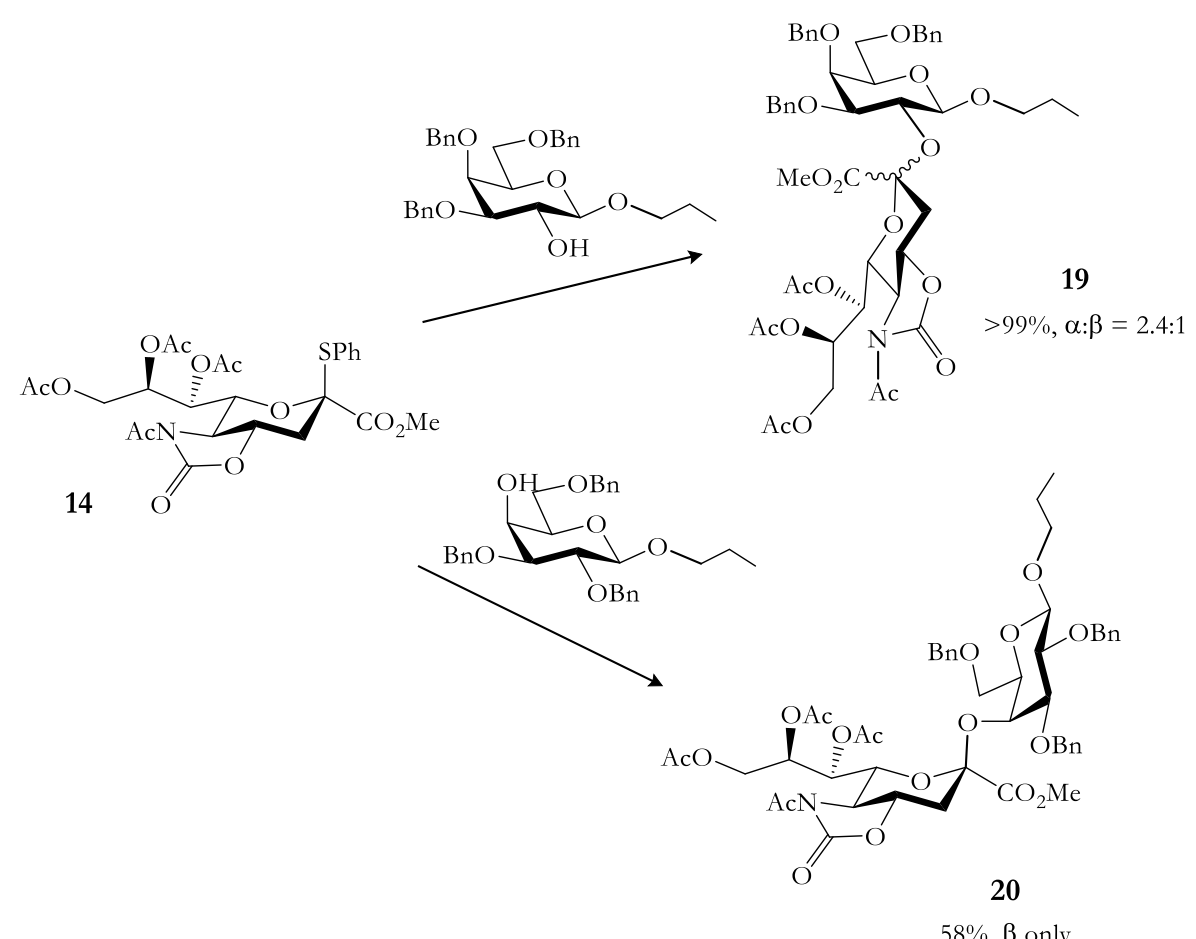

Figure 5. Synthesis of (2,2)- and (2,4) linked GM4 derivatives. Sialylation conditions: NIS/TfOH, MS 3A, $\mathrm{CH}_{3} \mathrm{CN} / \mathrm{CH}_{2} \mathrm{Cl}_{2}, 40^{\circ} \mathrm{C}$. 


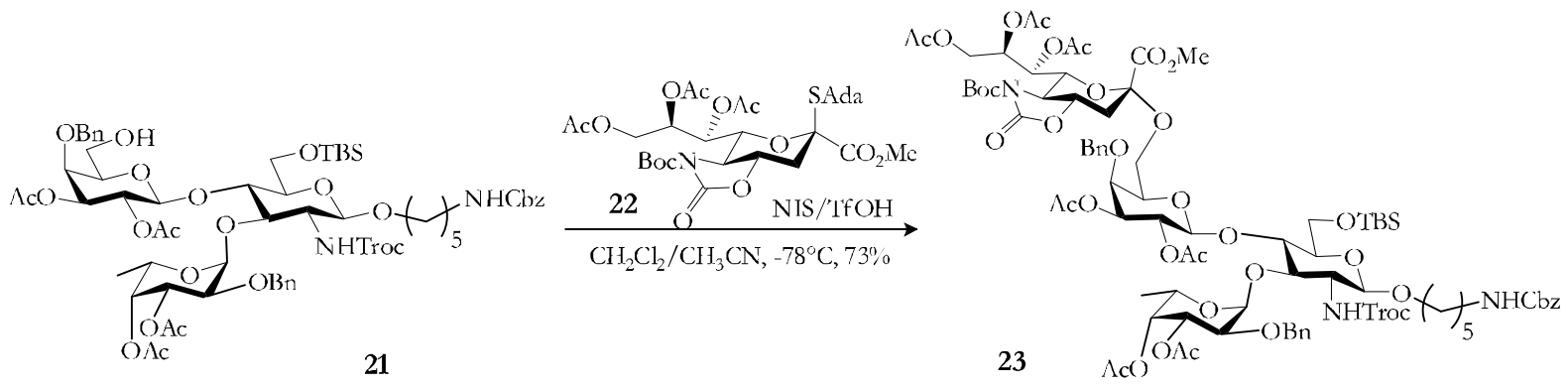

Figure 6. Synthesis of a tetrasaccharide bearing a fucose residue using 5-N-Boc-protected 5N,4O-oxarolidinone thiosialoside donor.

group's electron-withdrawing characteristic, oxazolidinthione protection of thiosialosides have also been investigated (Rajender and Crich, 2013). However, activation using $\mathrm{NIS} / \mathrm{TfOH}$ was only effective at higher temperature $\left(-50^{\circ} \mathrm{C}\right)$ and $\alpha$-sialylation results did not fare better than previously reported $\mathrm{N}$-acetyl (Crich and Li, O-Sialylation, 2007; Crich and $\mathrm{Li}, \alpha$-Selective, 2007) and $\mathrm{N}$ acetoxyacetimide oxazolidinone thiosialosides (Crich and Wu, 2008).

On the other hand, the isothiocyanate 27 byproduct in the oxazolidinthione-protected sialoside synthesis proved to be an excellent donor. Using various acceptors, $\alpha(2,3), \alpha(2,6)$ and $\alpha(2,9)$ sialylations were effected in moderate to high yields with perfect $\alpha$-selectivity. Most notable was the $\alpha(2,3)$ sialylation with the usually low reactive 4-O-benzyl-galactopyranoside acceptor which afforded disaccharide $\mathbf{2 8}$ only as the $\alpha$-anomer in $87 \%$ yield (Figure 8 ). Further diversification after coupling was also possible

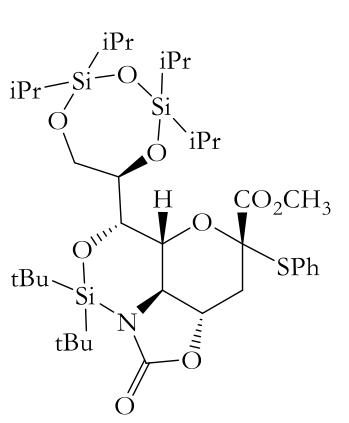

24

Figure 7. Sialylation using thiosialoside donor doublelocked by silylene and oxazolidinone groups. by modifying the isothiocyanate moiety. This gave the deamino disaccharide 29 in $78 \%$, protected glycolyl amide 30 in $55 \%, 31$ in $50 \%$, thiourea 32 in $90 \%$, isothiourea 33 in $80 \%$ and guanidine 34 in $49 \%$ yield (Mandhapati et al., 2015).

Other electron-withdrawing groups have also been employed for C5 protection. Attachment of N,N-acetyl, benzoyl group at C5 of a perbenzoylated $(\mathrm{Bz}$ protection at $\mathrm{C} 4,7,8$ and 9) thiosialoside activated using NIS/TfOH or $\mathrm{Ph}_{2} \mathrm{SO} / \mathrm{Tf}_{2} \mathrm{O}$, however, have resulted primarily in $\beta$-sialosides (Wang and Ye, 2009). This surprising result was suggested to be a consequence of the strong $\beta$-directing effects of the per-O-benzoylation in the donor. In particular, bulky groups such as tertbutyldimethylsilyl (TBDMS) and Bz attached at $\mathrm{C} 4$ and $\mathrm{C} 7$, respectively, were found to significantly influence the resulting stereoselectivity of the sialylation reaction (Premathilake et al., 2012).

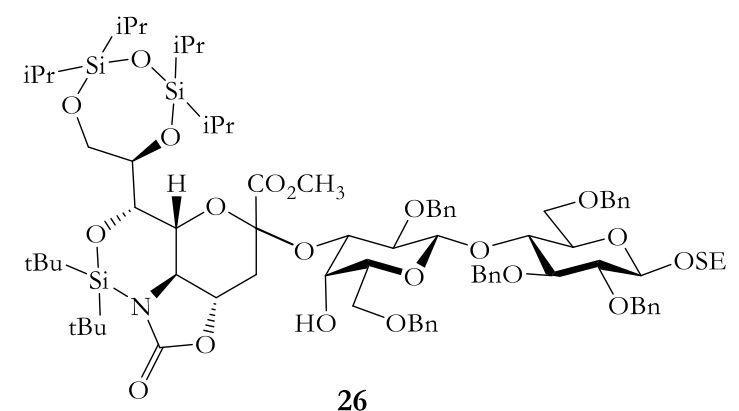
26

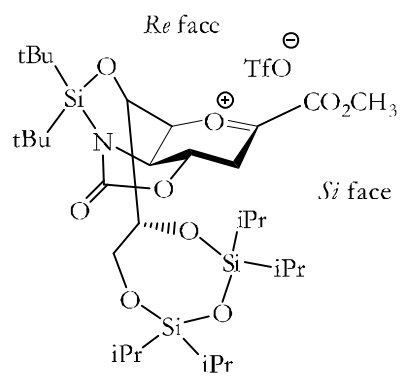

KIMIKA • Volume 27, Number 2, July 2016 


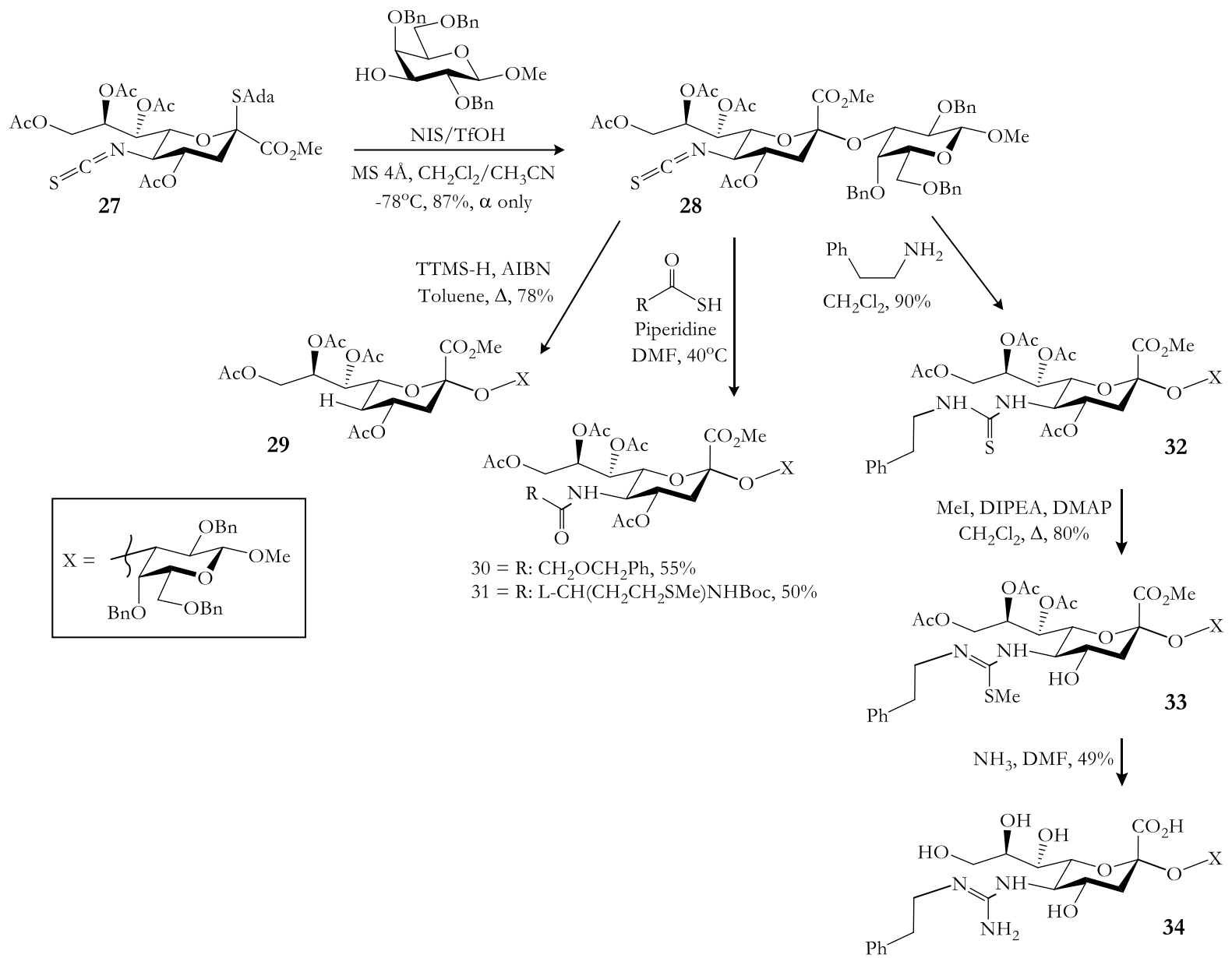

Figure 8. a-Sialylation using isothiocyanate-protected adamantanyl thiosialoside and subsequent diversification of the resulting disaccharide.

A sialyl donor with a modified ureido group in C5 have also been introduced recently (Table 2). Activation of 35 using iodine monobromide/silver trifluoromethanesulfonate (IBr/AgOTf) afforded (2,6)-linked sialosides 36 and 37 in $80 \%$ yield and $\operatorname{good} \alpha$ selectivity. Utilizing an excess amount of $\mathbf{3 5}$ in $(2,3)$ sialylation resulted in disaccharide $\mathbf{3 8}$ with $94 \%$ yield and $\alpha / \beta$ ratio of 24.6:1. To ease the purification process, 1,5-lactamization involving $\mathrm{C} 1$ and the nitrogen atom of the ureido group was performed using 1,8diazabicyclo-[5.4.0] undec-7-ene (DBU) in $N$, $N$-dimethylformamide (DMF) at $120^{\circ} \mathrm{C}$. After the incorporation of Boc on the lactam ring and treatment with sodium methoxide in methanol, the $\alpha$-sialosides can be obtained in excellent yields (Tanase et al., 2016).

\section{CONCLUSION}

Progress in chemical sialylation has led to the development of various promoters, solvent systems, donors and acceptors. All of which are aimed toward better yield and $\alpha$-selectivity. While excellent yields were already seen in past syntheses, achieving perfect $\alpha$-selectivity remains a challenge. This is because the inherent characteristics of sialic acids mostly favour the production of $\beta$-sialosides, which are not common in nature. Sialic acids in humans and animals are usually found to exist in $\alpha$-linkages with glycoconjugates. Thus, the need for structural modifications in the sialyl donor. Of these, attachment of oxazolidinone group at $\mathrm{C} 4$ and $\mathrm{C} 5$ has been very promising in improving both yield and $\alpha$-selectivity, even without the assistance of nitrile solvents. Oxazolidinone-protection has afforded the synthesis of $\alpha(2,3), \alpha(2,6), \alpha(2,8), \alpha(2,9)$-linked sialic acids and even non-natural sialosides 
Table 2. Sialylation of 5-Ureido Modified Donor 35 with 3- and 6-OH Acceptors.

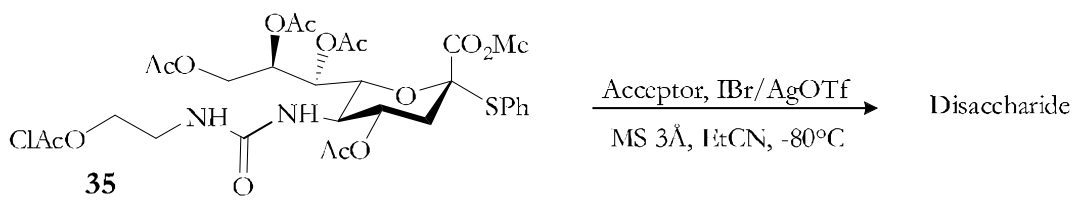

Acceptor

with $\alpha(2,2)$ and $\alpha(2,4)$ linkages. It has also allowed the assembly of dodecasialic acids at impressive yields and selectivity notwithstanding the length of the chain. Other C5 modifications such as the attachment of a modified ureido group has also facilitated easier purification of the $\alpha$ sialosides through 1,5-lactamization.

However, limited mechanistic work has been undertaken to explain many of these results and reactions are still carried out as small-scale experiments. Furthermore, the number of steps in the overall synthesis and ease of purification are also issues that must be addressed if large-scale synthesis is to be done for the production of vaccines and/or therapeutic agents. Future synthetic work may also include structural modifications on 2keto-3-deoxy-D-glycero-D-galacto-nononic acid (KDN) and N-glycolyl-neuraminic acid (Neu5Gc) as these sialic acid derivatives have as well been implicated in tumorigenesis.

\section{REFERENCES}

Abregu AV, Genta SB, Sanchez Riera AN, Sanchez SS. Immunohistochemical detection of hepatic GM1 and GM2 gangliosides in streptozotocin-induced diabetic rats. Hepatol. Res. 2002; 24:256-264.

Boltje TJ, Heise T, Rutjes FPJT, van Delft FL. A divergent method to prepare 5-amino-, 5$\mathrm{N}$-acetamido-, and 5-N-glycolylsialosides. Eur. J. Org. Chem. 2013; 24:5257-5261.

Boons G-J, Demchenko AV. Recent advances in O-sialylation. Chem. Rev. 2000; 100(12):4539-4565.

Byrne B, Donohoe GG, O'Kennedy R. Sialic acids: carbohydrate moieties that influence the biological and physical properties of biopharmaceutical proteins and living cells. Drug. Discov. Today. 2007; 12(7-8):319-326.

Chu K-C, Ren C-T, Lu C-P, Hsu C-H, Sun T$\mathrm{H}$, Han J-L, et al. Efficient and stereoselective synthesis of $\alpha(2,9)$ oligosialic acids: from monomers to dodecamers. Angew. Chem. Int. Ed. 2011; 50:9391-9395. 
Crich, D. Methodology development and Physical Organic Chemistry: A powerful combination for the advancement of Glycochemistry. J. Org. Chem. 2011; 76(22): 9193-9209.

Crich D, Li W. Efficient glycosidation of a phenyl thiosialoside donor with diphenyl sulfoxide and triflic anhydride in dichloromethane. Org. Lett. 2006; 8(5):959962.

Crich D, Li, W. O-Sialylation with $N$-acetyl-5$\mathrm{N}, 4-\mathrm{O}$-carbonyl-protected thiosialoside donors in dichloromethane: facile and selective cleavage of the oxazolidinone ring. J. Org. Chem. 2007; 72:2387-2391.

Crich D, Li W. $\alpha$-Selective sialylations at -78 ${ }^{\circ} \mathrm{C}$ in nitrile solvents with a 1-adamantanyl thiosialoside. J. Org. Chem. 2007; 72:77947797.

Crich D, Wu B. Stereoselective iterative onepot synthesis of $\mathrm{N}$-glycolylneuraminic acidcontaining oligosaccharides. Org. Lett. 2008; 10 (18):4033-4035.

De Meo C, Priyadarshani U. C-5 modifications in $\mathrm{N}$-acetyl-neuraminic acid: scope and limitations. Carbohydr. Res. 2008; 343:1540-1552.

Farris MD, De Meo C. Application of 4,5$O, N$-oxazolidinone protected thiophenyl sialosyl donor to the synthesis of $\alpha$-sialosides. Tetrahedron Lett. 2007; 48:1225-1227.

Gu Z-y, Zhang J-x, Xing G-w. N-acetyl-5$\mathrm{N}, 4-\mathrm{O}$-oxazolidinone-protected sialyl sulfoxide: An $\alpha$-selective sialyl donor with $\mathrm{Tf}_{2} \mathrm{O} /(\mathrm{Tol})_{2} \mathrm{SO}$ in dichloromethane. Chem. Asian J. 2012; 7(7):1524-1528.

Halcomb RL, Chappell MD. Recent developments in technology for glycosylation with sialic acid. J. Carbohydr. Chem. 2002; 21(7-9):723-768.
Hanashima, S. Recent strategies for stereoselective sialylation and their application to the synthesis of oligosialosides. Trends Glycosci. Glycotechnol. 2011; 23(131):111121.

Hanashima S, Sato K, Ito Y, Yamaguchi Y. Silylene/oxazolidinone double-locked sialic acid building blocks for efficient sialylation reactions in dichloromethane. Eur. J. Org. Chem. 2009; (25):4215-4220.

Harris BN, Patel PP, Gobble CP, Stark MJ, De Meo C. C-5 Modified S-Benzoxazolyl Sialyl Donors: Towards More Efficient Selective Sialylations. Eur. J. Org. Chem. 2011; 20-21: 4023-4027.

Hasegawa A, Nagahama T, Ohki H, Hotta K, Ishida $\mathrm{H}$, Kiso M. Synthetic studies on sialoglycoconjugates 25: Reactivity of glycosyl promoters in $\alpha$-glycosylation of $\mathrm{N}$-acetylneuraminic acid with the primary and secondary hydroxyl groups in the suitably protected galactose and lactose derivatives. J. Carbohydr. Chem. 1991; 10(3):493-498.

Hemeon I, Bennet AJ. Sialic acid and structural analogues: stereoselective syntheses. Synthesis. 2007; (13):1899-1926.x..207

Hussain MRM, Din N, Hassan M, Razaq A, Iqbal Z. Physiological significance of Fuc and Sialic acid containing glycans in the body. Arabian Journal of Chemistry 2011; doi:10.1016/j.arabjc.2011.06.028.

Ibrahim MA, Abdulkadir A, Onojah A, Sani L, Adamu A, Abdullahi H. Modulation of sialic acid levels among some organs during insulin resistance or hyperglycemic states. Mol. Cell Biochem. 2016; 411:235-239.

Ingraham HA, Alhadeff JA. Characterization of sialyltransferase in noncancerous and neoplastic human liver tissue. J. Natl. Cancer Inst. 1978; 61(6):1371-1374. 
Kancharla PK, Navuluri C, Crich D. Dissecting the influence of oxazolidinones and cyclic carbonates in sialic acid chemistry. Angew. Chem. Int. Ed. 2012; 51 (44):1110511109.

Kiefel MJ, von Itzstein M. Recent advances in the synthesis of sialic acid derivatives and sialylmimetics as biological probes. Chem. Rev. 2002; 102(2):471-490.

Kurimoto K, Yamamura H, Miyagawa A. Chemical approach for the syntheses of GM4 isomers with sialic acid to non-natural linkage positions on galactose. Carbohydr. Res. 2015; 401:39-50.

Leung HSY, Li OTW, Chan RWY, Chan MCW, Nicholls JM, Poon LLM. Entry of influenza $A$ virus with $\alpha 2,6$-linked sialic acid binding preference requires host fibronectin. J. Virol. 2012; 86(19):10704-10713.

Liang F-F, Chen L, Xing G-W. $\alpha$-Selective sialylations with $N$-acetyl-5-N,4-Ooxazolidinone-protected $p$-toluenethiosialoside. Synlett 2009; 3:425-428.

Liao G, Zhou Z, Guo Z. Synthesis and immunological study of $\alpha$-2,9-oligosialic acid conjugates as anti-group $C$ meningitis vaccines. Chem Commun. 2015; 51(47): 9647-50.

Lin C-C, Lin N-P, Sahabuddin LS, Reddy VR, Huang L-D, Hwang KC, et al. 5-N,4-OCarbonyl-7,8,9-tri-O-chloroacetyl-protected sialyl donor for the stereoselective synthesis of $\alpha$-(2,9)-tetrasialic acid. J. Org. Chem. 2010; 75 (15):4921-4928.

Loo YH, Hyde KR, Lin FH, Wisniewski HM. Cerebral biochemical abnormalities in experimental maternal phenylketonuria: gangliosides and sialoglycoproteins. Life Sci. 1985; 37:2099-2109.

Lundblad A. Gunnar Blix and his discovery of sialic acids. Fascinating molecules in Glycobiology. Ups. J. Med. Sci. 2015; 120:104112.
Mandal C, Schwartz-Albiez R, Vlasak R. Functions and biosynthesis of $\mathrm{O}$-acetylated sialic acids. Top. Curr. Chem. 2015; 366:1-30.

Mandhapati AR, Rajender S, Shaw J, Crich D. The isothiocyanato moiety: an ideal protecting group for the stereoselective synthesis of sialic acid glycosides and subsequent diversification. Angew. Chem. Int. Ed. 2015; 54(4): 12751278.

Matrosovich M, Herrler G, Klenk HD. Sialic acid receptors of viruses Top. Curr. Chem. 2015; 367:1-28.

Nicol BM, Prasad SB. Sialic acid changes in Dalton's lymphoma-bearing mice after cyclophosphamide and cisplatin treatment. Braz. J. Med. Biol. Res. 2002; 35(5):549-553.

Pekosz A, Newby C, Bose PS, Lutz A. Sialic acid recognition is a key determinant of influenza $A$ virus tropism in murine trachea epithelial cell cultures. Virology 2009; 386:61-67.

Piras F, Schiff M, Chiapponi C, Bossu P, Muhlenhoff M, Caltagirone C, et al. Brain structure, cognition and negative symptoms in schizophrenia are associated with serum levels of polysialic acid-modified NCAM. Transl. Psychiatry. 2015; 5:1-6.

Premathilake HD, Gobble CP, Pornsuriyasak P, Hardimon T, Demchenko AV, De Meo C. How O-substitution of sialyl donors affects their stereoselectivity. Org. Lett. 2012; 14(4):1126-1129.

Rajender S, Crich D. Exploration of the oxazolidinthione protecting system for the synthesis of sialic acid glycosides. J. Carbohydr. Chem. 2013; 32:324-335.

Ress DK, Linhardt RJ. Sialic acid donors: Chemical synthesis and glycosylation. Curr. Org. Synth. 2004; 1(1):31-46. 
Salmasan RM, Manabe Y, Kitawaki Y, Chang T-C, Fukase K. Efficient glycosylation using $\operatorname{In}(\mathrm{OTf})_{3}$ as a lewis acid: Activation of $\mathrm{N}$ phenyltrifluoroacetimidate or thioglycosides with halogenated reagents or PhIO. Chem. Lett. 2014; 43:956-958.

Sanchez SS, Abregu AV, Aybar MJ, Sanchez Riera AN. Changes in liver gangliosides in streptozotocin-induced diabetic rats. Cell Biol. Int. 2000; 24(12):897-904.

Sauer A-K, Liang C-H, Stech J, Peeters B, Quere P, Schwegmann-Wessels C, et al. Characterization of the sialic acid binding activity of influenza A viruses using soluble variants of the $\mathrm{H} 7$ and $\mathrm{H} 9$ hemagglutinins. PLoS One 2014; 9(2): e89529.

Sato C, Kitajima K. Impact of structural aberrancy of polysialic acid and its synthetic enzyme ST8SIA2 in schizophrenia. Front Cell Neurosci. 2013; 7:1-11.

Schauer R. Achievements and challenges of sialic acid research. Glycoconj. J. 2000; 17 (7):485-499.

Schedin-Weiss S, Winblad B, Tjernberg L. The role of protein glycosylation in Alzheimer disease. FEBS J. 2014; 281:46-62.

Schnaar R, Gerardy-Schahn R, Hildebrandt H. Sialic acids in the brain: gangliosides and polysialic acid in nervous system development, stability, disease, and regeneration. Physiol. Rev. 2014; 94:461-518.

Sirota P, Bessler H, Allalouf D, Djaldetti M, Levinsky H. Sialic acid in platelets of schizophrenic patients. Prog. Neuropsychopharmacol. Biol. Psychiatry. 1988; 12:103-107.

Spence S, Greene MK, Fay F, Hams E, Saunders SP, Hamid U, et al. Targeting Siglecs with a sialic acid-decorated nanoparticle abrogates inflammation. Sci. Transl. Med. 2015; 7(303):303ra140.
Suzuki K. The pattern of mammalian brain gangliosides-III: regional and developmental differences. J. Neurochem. 1965; 12 (12):969979.

Suzuki Y, Ito T, Suzuki T, Holland RE Jr, Chambers TM, Kiso M, et al. Sialic acid species as a determinant of the host range of influenza A viruses. J. Virol. 2000; 74(24): 11825-11831.

Stencel-Baerenwald JE, Reiss K, Reiter DM, Stehle T, Dermody TS. The sweet spot: defining virus-sialic acid interactions. Nat. Rev. Microbiol. 2014; 12(11):739-749.

Tanaka H, Nishiura $Y$, Takahashi T. Stereoselective synthesis of oligo- $\alpha$ - $(2,8)$-sialic acids. J. Am. Chem. Soc. 2006; 128:7124-7125.

Tanaka H, Nishiura Y, Takahashi T. Stereoselective synthesis of $\alpha(2,9)$ di- to tetrasialic acids, using a 5,4-N,O-carbonyl protected thiosialoside. J. Org. Chem. 2009; 74:4383-4386.

Tanase M, Imamura A, Ando $\mathrm{H}$, Ishida $\mathrm{H}$, Kiso M. A 5-ureido-modified sialyl donor: A tool for the synthesis of $\alpha$-sialosides. Org. Lett. 2016; 18 (6): 1454-1457.

Varki A. Biological roles of oligosaccharides: all of the theories are correct. Glycobiology. 1993; 3(2):97-130.

Varki A, Gagneux P. Multifarious roles of sialic acids in immunity. Ann. N.Y. Acad. Sci. 2012; 1253:16-36.

Varki A, Schauer R. Sialic Acids. In Varki A, Cummings RD, Esko JD, et al., editors. Essentials of Glycobiology. 2nd ed. New York: Cold Spring Harbor Laboratory Press; 2009. p. 1-18.

Wang B, Brand-Miller J. The role and potential of sialic acid in human nutrition. Eur. J. Clin. Nutr. 2003; 57:1351-1369. 
Wang B, Brand-Miller J, McNeil Y, McVeagh P. Sialic acid concentration of brain gangliosides: variation among eight mammalian species. Comp. Biochem. Physiol. 1998; 119A(1):435-439.

Wang Y-J, Jia J, Gu Z-Y, Liang F-F, Li R-C, Huang $\mathrm{M}-\mathrm{H}$, et al. Tunable stereoselectivity during sialylation using an $\mathrm{N}$-acetyl-5-N,4-Ooxazolidinone-protected p-toluene 2-thio sialoside donor with $\mathrm{Tf}_{2} \mathrm{O} / \mathrm{Ph}_{2} \mathrm{SO} / \mathrm{TTBPy}$. Carbohydr. Res. 2011; 346:1271-1276.
Wang Y, Ye X-S. Sialylation reactions with N,N-acetyl, benzoyl-O-perbenzoyl-protected sialyl donor. Tetrahedron Lett. 2009; 50:38233826.

Zhang T, She Z, Huang Z, Li J, Luo X, Deng $Y$. Application of sialic acid/polysialic acid in the drug delivery systems. Asian J Pharm Sci. 2014; 9(2):75-81. 